\title{
Synthesis of Hybrid Organo-Inorganic Materials Based on $\alpha-\mathrm{Ni}(\mathrm{OH})_{2}$
}

\author{
Elena V. Pikurova*a, \\ Svetlana V. Saikova ${ }^{\text {a,b }}$, Dmitry I. Chistyakov ${ }^{\mathrm{b}}$, \\ Irina V. Korol'kova ${ }^{a}$ and Alexander S. Samoilo ${ }^{b}$ \\ anstitute of Chemistry and Chemical Technology SB RAS \\ $F R C$ "Krasnoyarsk Scientific Center of the SB RAS" \\ 50/24 Akademgorodok, Krasnoyarsk, 660036, Russia \\ ${ }^{b}$ Siberian Federal University \\ 79 Svobodny, Krasnoyarsk, 660041, Russia
}

Received 02.11.2018, received in revised form 27.01.2019, accepted 07.02.2019

\begin{abstract}
In the paper we present a method for producing hybrid organo-inorganic materials based on $\alpha-\mathrm{Ni}(\mathrm{OH})_{2}$. This materials were synthesized by the anion resin exchange precipitation of nickel nitrate in the presence of sodium dodecyl sulfate or cetyltrimethylammonium bromide (CTAB) using the strong base anion exchange resin $A B-17-8$ in the $O H$-form as a precipitate agent. The as-obtained products were studied by methods X-ray diffraction, infrared spectroscopy, complex thermal analysis and TEM.
\end{abstract}

Keywords: synthesis, anion exchange resin precipitation, hybrid materials, nickel, nanoparticles.

Citation: Pikurova E.V., Saikova S.V., Chistyakov D.I., Korol'kova I.V., Samoilo A.S. Synthesis of hybrid organo-inorganic materials based on $\alpha-\mathrm{Ni}(\mathrm{OH})_{2}$, J. Sib. Fed. Univ. Chem., 2019, 12(1), 31-41. DOI: 10.17516/1998-2836-0106.

(C) Siberian Federal University. All rights reserved

* Corresponding author E-mail address: vitaelen@gmail.com 


\title{
Синтез гибридных органо-неорганических материалов на основе $\alpha-\mathrm{Ni}(\mathrm{OH})_{2}$
}

\author{
Е.В. Пикурова ${ }^{a}$, С.В. Сайкова ${ }^{\mathrm{a}, \tilde{\sigma}}$, \\ Д.И. Чистяков ${ }^{\tilde{\sigma}}$, И.В. Королькова ${ }^{\mathrm{a}}$, А.С. Самойло \\ ${ }^{a}$ Институт химии и химической технологии СО РАН \\ ФИЦ «Красноярский научный иентр СО РАН» \\ Россия, 660036, Красноярск, Академгородок, 50/24 \\ ${ }^{6}$ Сибирский федеральный университет \\ Россия, 660041, Красноярск, пр. Свободный, 79
}

В работе предложен способ получения гибридных органо-неорганических материалов (ГОНМ) на основе $\alpha-\mathrm{Ni}(\mathrm{OH})_{2}$. Образование ГОНМ происходит в результате анионообменного осаждения нитрата никеля в присутствии додецилсульфата натрия или бромида цетилтриметиламмония (ЦТАБ) с использованием в качестве осадителя сильноосновного анионита АВ-17-8 в ОН-форме. Полученные продукты исследованы методами РФА, ИКспектроскопии, комплексным термическим анализом и ПЭМ.

Ключевые слова: гибридные материалы, никель, анионит, осаждение, наночастицы.

\section{Введение}

В настоящее время гибридные органо-неорганические материалы (ГОНМ) привлекают повышенное внимание благодаря своим уникальным механическим, магнитным и оптоэлектронным свойствам. Они находят применение в различных областях науки, техники, медицины и биотехнологии. Так, материалы на основе диоксида титана проявляют высокую фотоактивность, что делает их перспективными для фотокатализа $[1,2]$. ГОНМ на основе металлоорганических люминофоров и неорганических стекол подходят для создания новых светоизлучающих устройств [3, 4]; гибридные нанокомпозиты на основе диоксида кремния, содержащего различные органические соединения, используются в качестве катализаторов, адсорбентов для фармацевтической и косметической промышленности и т.д. [5, 6]. Кроме того, ГОНМ могут выступать в качестве прекурсоров для получения наноразмерных металлических или оксидных частиц [7-14].

Одним из способов, позволяющих получать ГОНМ, является интеркаляция - обратимая реакция внедрения различных реагентов («гость») в межслоевое пространство кристаллических веществ со слоистым типом структуры («хозяин»). Интеркаляция приводит к изменению межслоевого расстояния при наличии стерического фактора и перераспределению электронной плотности, а также стабилизирует структуру вследствие кулоновского взаимодействия между внедренными ионами и слоями структуры [15]. В качестве «хозяев» применяют графит, слоистые оксиды металлов, оксихлориды, слоистые двойные гидроксиды, силикатные глины и другие материалы. Роль «гостей» исполняют органические и неорганические молекулы, ионы и атомы металлов, металлоорганические соединения [13, 14, 16-18]. Процесс интеркаляции на 
практике осуществляют либо посредством реакции ионного обмена между вводимыми анионами и первоначально содержащимися в составе анионами слоистого материала, либо совместным осаждением компонентов из растворов («one-pot» синтез) [19].

Среди большого круга соединений слоистого типа, применяемых в качестве «хозяина», несомненный интерес представляют гидроксиды переходных металлов, которые схожи по своему строению с гидротальцитподобными соединениями. Их структура представляет собой систему из положительно заряженных гидроксидных слоев, заряд которых нейтрализуется межслоевыми анионами, ассоциированными с различными количествами воды [19]. Гидроксид никеля - типичный представитель таких слоистых материалов. Он находит важное применение в щелочных Ni-Cd, Ni-Zn, Ni-Fe и Ni-MH аккумуляторах, суперконденсаторах, в качестве прекурсора для создания катализаторов $[17,18,20]$. Известно, что $\mathrm{Ni}(\mathrm{OH})_{2}$ кристаллизуется в виде двух полиморфных модификаций, обозначающихся как $\alpha$ и $\beta$. В случае $\beta-\mathrm{Ni}(\mathrm{OH})_{2}$, имеющего бруситоподобную структуру, гексагонально упакованные гидроксидные слои располагаются один над другим, при этом расстояние между ними составляет 4,6 (рис. 1a). Кристаллографическое изучение этой полиморфной модификации выявило отсутствие интеркалированных ионов между этими слоями $[20,21] . \alpha-\mathrm{Ni}(\mathrm{OH})_{2}$ состоит из нестехиометрических гидроксидных слоев, избыточный положительный заряд которых компенсируется внедрением анионов $\left(\mathrm{NO}_{3}^{-}, \mathrm{CO}_{3}^{2-}, \mathrm{Cl}^{-}\right.$и др.) и молекул воды в межслоевое пространство, что приводит к существенному увеличению расстояния между слоями - до 7-8 $\AA$ [20]. Кроме того, структура $\alpha$-модификации является турбостратной, т.е. слои дезориентированы друг относительно друга (рис. 1б).

Таким образом, для получения ГОНМ наибольший интерес из двух полиморфных форм представляет $\alpha-\mathrm{Ni}(\mathrm{OH})_{2}$, имеющая большее межслоевое расстояние и подвижные анионы (А), которые в процессе интеркаляции могут обмениваться на более крупные (рис. 16). Как следствие, расширяется пространство между слоями матрицы, что в результате придает новые свойства материалу.

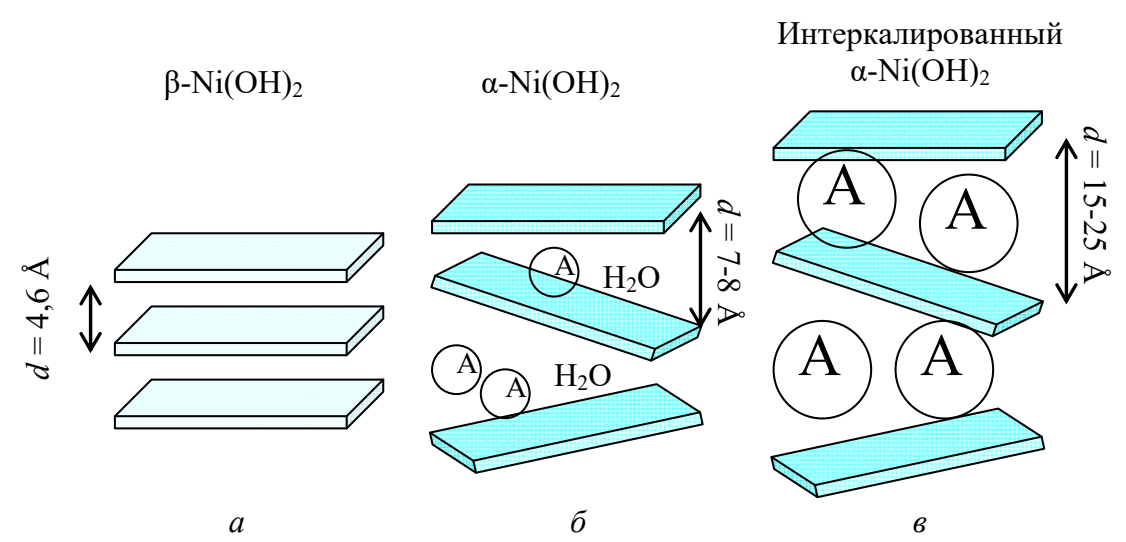

Рис. 1. Схематическое изображение $\beta$-модификации (a), $\alpha$-модификации (б), а также интеркалированного $\alpha-\mathrm{Ni}(\mathrm{OH})_{2}$ (в), полученного в данной работе

Fig. 1. Structure models of $\beta-$ (а), $\alpha-\left(\right.$ б) $\mathrm{Ni}(\mathrm{OH})_{2}$ modifications, and intercalated $\mathrm{Ni}(\mathrm{OH})_{2}(\mathrm{~B})$ obtained in this work 
В литературе приводятся различные способы получения и составы ГОНМ на основе $\alpha-\mathrm{Ni}(\mathrm{OH})_{2}$. Так, в работе [20] гидротермальным методом, обрабатывая в автоклаве при $140{ }^{\circ} \mathrm{C}$ в течение 10 ч $\alpha-\mathrm{Ni}(\mathrm{OH})_{2}$ различными неорганическими солями, синтезировали ряд материалов, содержащих от 5 до $20 \%$ анионов $\left(\mathrm{Cl}^{-}, \mathrm{CH}_{3} \mathrm{COO}^{-}, \mathrm{SO}_{4}{ }^{2-}\right.$ или $\left.\mathrm{NO}_{3}^{-}\right)$, а также молекулы уротропина. По данным РФА, значения межслоевого расстояния полученных продуктов лежали в интервале от 7,2 до $15,1 \AA$, они обладали высокой стабильностью в сильнощелочных растворах.

В работе [18] методом химического осаждения нитрата никеля гексаметилентетрамином в присутствии додецилсульфата натрия (ДСН) в автоклавных условиях при $120{ }^{\circ} \mathrm{C}$ синтезировали ГОНМ состава $\mathrm{Ni}(\mathrm{OH})_{1.65}\left(\mathrm{C}_{12} \mathrm{H}_{25} \mathrm{SO}_{4}\right)_{0.33}\left(\mathrm{NO}_{3}\right)_{0.02} \bullet 0.7 \mathrm{H}_{2} \mathrm{O}$ с межслоевым расстоянием $26,9 \AA$. После расщепления этого материала были получены гексагональные нанопластины $\mathrm{Ni}(\mathrm{OH})_{2}$ толщиной в 1 нм. В [22] интеркалированный $\alpha$-гидроксид никеля получали соосаждением ацетата никеля и ДСН раствором аммиака. Согласно данным РФА, межслоевое расстояние в продукте составило $31 \AA$ А́.

Известно, что $\alpha$-модификация $\mathrm{Ni}(\mathrm{OH})_{2}$ метастабильна, ее трудно получить традиционными способами - осаждением щелочью или аммиаком при комнатных температурах, поэтому в большинстве работ синтез ГОНМ проводят в автоклавах при высоких температурах и давлениях. В данном исследовании мы предлагаем простой метод получения гибридных органонеорганических материалов без применения высоких температур и давлений и сложного оборудования. В качестве осадителя будет использован анионит АВ-17-8 в ОН-форме. Процесс анионообменного осаждения можно описать следующим уравнением:

$$
2 \mathrm{ROH}+\mathrm{Ni}\left(\mathrm{NO}_{3}\right)_{2} \rightarrow 2 \mathrm{RNO}_{3}+\mathrm{Ni}(\mathrm{OH})_{2} \downarrow,
$$

где $\mathrm{ROH}, \mathrm{RNO}_{3}$ - анионит AB-17-8 в ОН- и $\mathrm{NO}_{3}$ - формах.

Как видно из уравнения 1 , метод основан на обменной реакции между ионами, зафиксированными на смоле (например, $\mathrm{OH}^{-}$), и раствором, содержащим необходимый для осаждения ион. Как показали наши исследования [23, 24], ионообменная смола в этом случае не только служит источником ионов-осадителей, но и сорбирует мешающие ионы, решает проблемы однородности химического состава продукта. Также использование анионита позволяет получать гидроксид в мягких условиях при $\mathrm{pH}=6-7$, т.е. без создания сильнощелочной среды, которая способствует образованию $\beta-\mathrm{Ni}(\mathrm{OH})_{2}[24]$.

\section{Экспериментальная часть}

В работе использовали следующие реактивы: нитрат никеля $\mathrm{Ni}\left(\mathrm{NO}_{3}\right)_{2} \cdot 6 \mathrm{H}_{2} \mathrm{O}$ (ч.д.а., фирма «Химреактивснаб»), цетилтриметиламмоний бромид $\mathrm{C}_{19} \mathrm{H}_{42} \mathrm{NBr}$ (ЦТАБ, 99 \%, фирма Panreac), додецилсульфат натрия $\mathrm{C}_{12} \mathrm{H}_{25} \mathrm{SO}_{4} \mathrm{Na}$ (ДСН, чда, фирма Panreac), декстран-40 10\%-й раствор $\mathrm{H}\left(\mathrm{C}_{6} \mathrm{H}_{10} \mathrm{O}_{5}\right) \mathrm{xOH}$ (фирма РУП «Белмедпрепараты»), гелевый сильноосновный анионит АВ-17-8 (ГОСТ 20298-74, фирма ПАО “АЗОТ”).

Подготовка анионита к эксплуатации: исходный анионит в хлоридной форме подвергали рассеву с целью выделения фракции с размером зерна 0,25-0,50 мм, отмывали от мономеров, заливая 1,0 M раствором $\mathrm{NaCl}$. Далее переводили в ионит в ОН-форму, обрабатывая 5 раз 2,0 M раствором $\mathrm{NaOH}$ при соотношении объёмов жидкой и твёрдой фаз, равном 3 , и выдерживая 
каждый раз по 1 ч. Сорбент отмывали водой до $\mathrm{pH}=6-7$, высушивали при $60{ }^{\circ} \mathrm{C}$ (полная обменная емкость $=2,2$ ммоль·экв/г) [25].

Получали гибридные органо-неорганические материалы «one-pot» синтезом при комнатной температуре: 11 г анионита приводили в контакт с раствором $\mathrm{Ni}\left(\mathrm{NO}_{3}\right)_{2}$ или его смесями с растворами ДСН, ЦТАБ или декстрана. Условия получения образцов даны в табл. 1. Реакционные смеси оставляли на 1 ч на шейкере при постоянном перемешивании (частота 200 встряхиваний в минуту). Затем анионит отделяли, пропуская смесь через сито с диаметром отверстий 0,25 мм, промывали дистиллированной водой и подвергали элюированию $1 \mathrm{M} \mathrm{HNO}_{3}$ (3 раза по 1 ч). Полученные осадки отделяли с помощью центрифугирования и высушивали при $80{ }^{\circ} \mathrm{C}$.

РегистрациюИК-спектров образцов осуществляли на ИК-Фурье-спектрометре IRTracer-100 (Shimadzu, Япония) в области 4000-400 см-1. Полученная спектральная информация была обработана с помощью пакета программ LabSolution. Термический анализ проводили на синхронном термическом анализаторе SDT Q600, совмещенном с ИК-Фурье-спектрометром Nicolet 380 c TGA/FT-IR интерфейсом (приставка для анализа газовой фазы). Данный комплекс позволял одновременно получать данные ДТА, ТГ и состав выделяющейся газовой фазы. Съемка термограмм проходила при нагревании со скоростью 20 К/мин в атмосфере воздуха, скорость продувки воздуха 50 мл/мин.

Съемка рентгенограмм осуществлялась на порошках в диапазоне углов $2^{\circ}<2 \Theta<15^{\circ}$ с шагом $0,03^{\circ}$ и скоростью сканирования 1,5 град/мин на автоматизированном рентгеновском дифрактометрическом оборудовании фирмы Shimadzu XRD-7000S (излучение $\mathrm{CuK}_{\alpha}$ ). РФА проводился с использованием информационно-поисковой системы рентгенофазовой идентификации материалов (ИПС ФИ), совмещающей качественный и полуколичественный (по методу «корундовых чисел») анализы. Исследование продуктов методом ПЭМ выполнено на просвечивающем электронном микроскопе НT-7700 (Hitachi, Япония).

\section{Обсуждение результатов}

Ранее [25] на примере $\alpha-\mathrm{Co}(\mathrm{OH})_{2}$ нами было показано, что при комнатной температуре и обычном давлении ГОНМ можно получить только в результате «one-pot» синтеза, а процесс постсинтетической обработки гидроксида не приводит к желаемому результату. В данной работе мы также использовали анионообменное осаждение металла в присутствии органических соединений: анионного (ДСН) и катионного ПАВ (ЦТАБ), а также полисахарида - декстрана. Для сравнения проведен синтез $\alpha-\mathrm{Ni}(\mathrm{OH})_{2}$ в отсутствии интеркалянтов (табл. 1, образец 1).

Скорость и полноту осаждения ионов $\mathrm{Ni}^{2+}$ определяли путем измерения электропроводности реакционной системы кондуктометрическим методом. В процессе анионообменного осаждения нитрат-анионы переходят в фазу анионита, а ионы никеля связываются с образующимися в ходе ионного обмена ОН-ионами в малорастворимый гидроксид, что приводит к снижению электропроводности раствора. На рис. 2 представлены зависимости степени осаждения никеля (С.о.) от времени для образцов 1-4 (табл. 1). Видно, что процесс идет довольно быстро, при этом выход продукта также высок, а фазой анионита удерживается не более 2-5 \% катионов металла.

Контролировать внедрение анионов в межслоевое пространство слоистого гидроксида можно посредством ИК-спектроскопии по появлению характеристических полос в его спектре. 
Таблица 1. Условия и результаты синтеза ГОНМ на основе $\alpha-\mathrm{Ni}(\mathrm{OH})_{2}$

Table 1. The reaction conditions and results of the synthesis of HONM from $\alpha-\mathrm{Ni}(\mathrm{OH})_{2}$

\begin{tabular}{|c|c|c|c|c|c|c|}
\hline \multirow[b]{2}{*}{ № образца } & \multicolumn{2}{|c|}{ Исходные реагенты } & \multirow[b]{2}{*}{ C.o., \% } & \multirow[b]{2}{*}{ Элюат, \% } & \multirow{2}{*}{$\begin{array}{c}\mathrm{M}_{\text {гонм }}, \text { г/моль } \\
\text { (по ДСК) }\end{array}$} & \multirow[b]{2}{*}{$\mathrm{X}$} \\
\hline & \multirow{5}{*}{$\begin{array}{c}\mathrm{Ni}\left(\mathrm{NO}_{3}\right)_{2} \\
+ \\
\mathrm{AB}-17-8(\mathrm{OH})\end{array}$} & $\begin{array}{c}\text { Органическое } \\
\text { соединение }\end{array}$ & & & & \\
\hline 1 & & - & 92 & 5 & 111 & - \\
\hline 2 & & ДСН & 95 & 5 & 150 & 0,16 \\
\hline 3 & & ЦТАБ & 85 & 5 & 136 & $\overline{0,06}$ \\
\hline 4 & & декстран & 98 & 2 & - & - \\
\hline
\end{tabular}

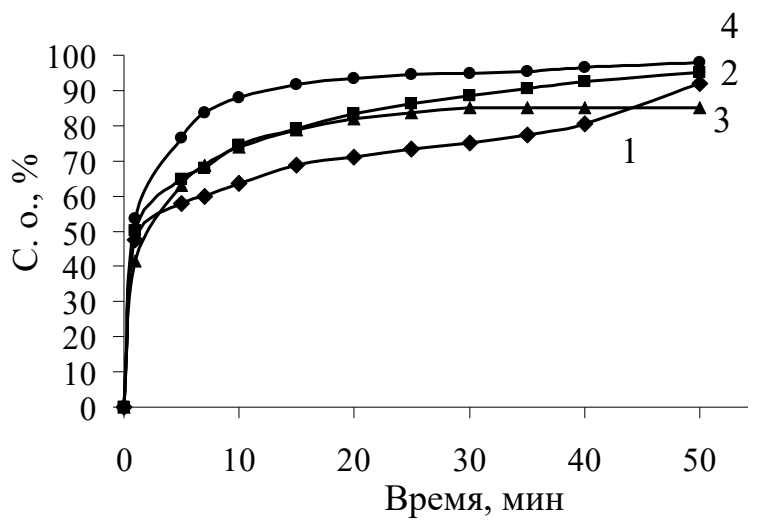

Рис. 2. Зависимость степени анионообменного осаждения от времени для образцов $\alpha-\mathrm{Ni}(\mathrm{OH})_{2}$, полученных в отсутствие органических добавок (1) и в присутствии ДСН (2), ЦТАБ (3) и декстрана (4)

Fig. 2. The time-dependence of the degree of anion resin exchange precipitation for $\alpha-\mathrm{Ni}(\mathrm{OH})_{2}$ samples obtained without organic additives (1) and with LTO (2), CTAB (3) or dextran (4)

На рис. 3 приведены ИК-спектры полученных образиов 1-4. Вид спектральных кривых образцов 3-4 практически не отличается от спектра исходного гидроксида никеля (образец 1): полосы поглощения при 837 и 1385-1470 см-1 соответствуют валентным колебаниям карбонат-ионов, находящихся в межслоевом пространстве и связанных электростатически. Широкий максимум поглощения около $3400 \mathrm{~cm}^{-1}$ относится к валентным колебаниям ОН-групп, связанных водородными связями, и характерен именно для $\alpha$-модификации $\mathrm{Ni}(\mathrm{OH})_{2}$, содержащей в межслоевом пространстве молекулы воды. Также наблюдается полоса поглощения при $\approx 1640 \mathrm{~cm}^{-1}$, относящаяся к деформационным колебаниям воды. Для $\beta-\mathrm{Ni}(\mathrm{OH})_{2}$ характерен острый узкий максимум при $3650 \mathrm{~cm}^{-1}$, который относят к колебаниям ОН-ионов, не связанных водородной связью, а также интенсивная полоса около $520 \mathrm{~cm}^{-1}$, приписываемая связи Ni-O [26, 27]. Эти максимумы поглощения отсутствуют во всех полученных образцах, однако на спектрах образцов 2 и 3 появляются дополнительные полосы поглощения в области 2854-2957 см-1, характерные для валентных колебаний алифатических $\mathrm{CH}_{3}$ - и $\mathrm{CH}_{2}$-групп, что свидетельствует о внедрении органических анионов [22] в образцы, полученные в присутствии ДСН и ЦТАБ.

Образиы 2-3 исследовали также комплексным термическим анализом (рис. 4). На кривых ДСК обоих образцов наблюдаются эндоэффекты при 118-138 ${ }^{\circ} \mathrm{C}$, обусловленные потерей ад- 


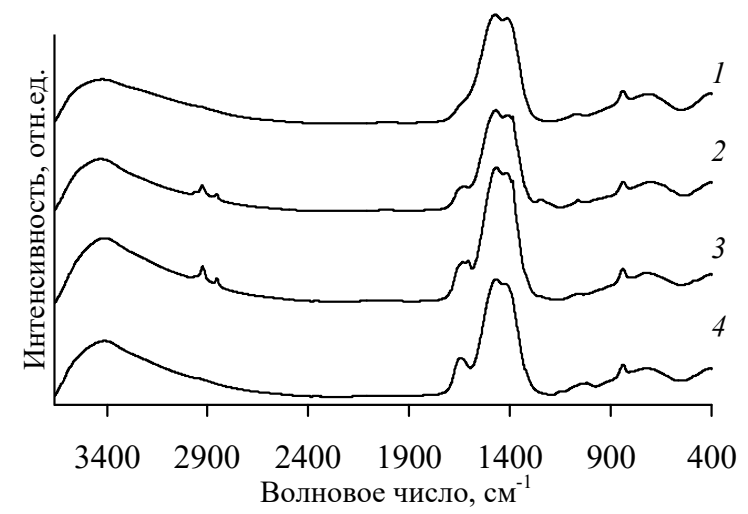

Рис. 3. ИК-спектры образцов 1-4 (табл. 1)

Fig. 3. IR spectra of 1-4 samples (see Table 1)
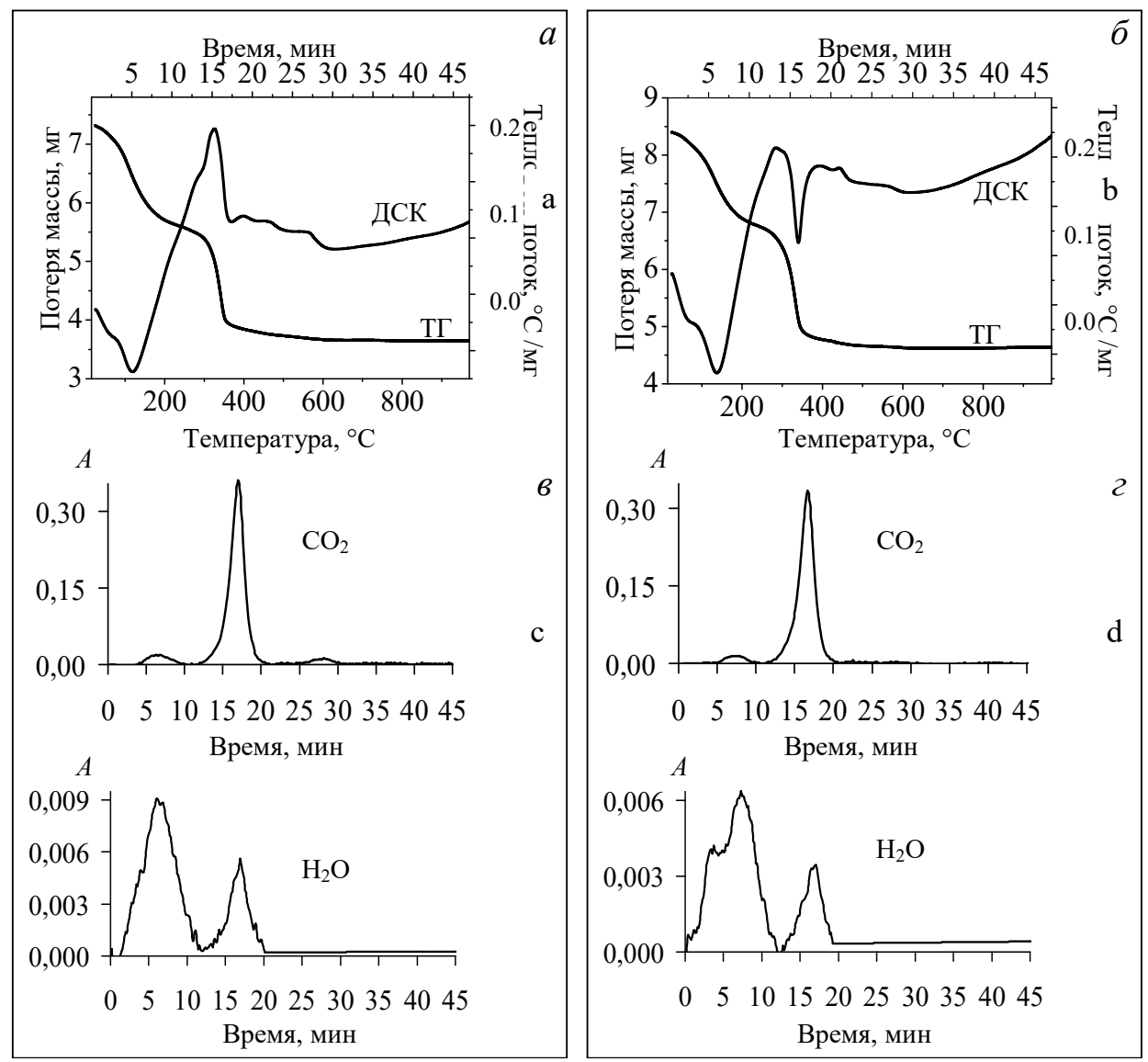

Рис. 4. Термограммы (кривые ТГ, ДСК) образца 2 (а) и образияа 3 (б) и зависимость оптической плотности выделяющихся газов $\left(\mathrm{H}_{2} \mathrm{O}, \mathrm{CO}_{2}\right)$ от времени (в, г)

Fig. 4. The DSC - TGA thermograms of sample 2 (a) and sample 3 (б), and the dependence of the optical density of the evolved gases $\left(\mathrm{H}_{2} \mathrm{O}, \mathrm{CO}_{2}\right)$ on time $(\mathrm{B}, \mathrm{r})$ 
сорбированной и межслоевой воды. Эндоэффект при $340{ }^{\circ} \mathrm{C}$ для образиа 3 (рис. $4 б$ ), по данным спектроскопического исследования отходящих газов (рис. 42), связан с дегидроксилированием слоев и деструкцией карбонат-анионов. Небольшой малозаметный (вследствие наложения на эндоэффект) экзоэффект при 300-310 ${ }^{\circ} \mathrm{C}$ обусловлен окислением органической части ГОНМ. На термограмме образиа 2 (рис. $4 a$ ) отражаются те же процессы. Однако экзоэффект (при $326^{\circ} \mathrm{C}$ ) в этом случае намного больше, что, вероятно, связано с большим содержанием органических анионов в образце. По данным термогравиметрии рассчитали молекулярную массу $\left(\mathrm{M}_{\text {гонм}}\right.$, г/моль) и оценили мольную долю (Х) органических анионов в полученных образцах (данные приведены табл. 1): $\alpha-\mathrm{Ni}(\mathrm{OH})_{2}$, полученный в присутствии ДСН, содержит около 16 мол. \% органической фазы, тогда как их содержание в образце, синтезированном в присутствии ЦТАБ, заметно ниже.

Основным структурным методом, позволяющим судить об интеркалировании анионов в межслоевое пространство слоистого материала, является рентгенофазовый анализ. Поскольку в большинстве случаев производят анионный обмен мелких анионов на более крупные, то судить о протекании данного процесса можно по увеличению межплоскостных расстояний между слоями $\mathrm{NiO}_{6}$, которые можно определить по дифрактограмме соединения. Полученные нами образы были рентгеноаморфны, однако в малоугловой области $\left(2^{\circ}<2 \Theta<15^{\circ}\right)$ рентгенограммы образиа 2, полученного в присутствии додецилсульфата натрия, наблюдался небольшой размытый максимум (рис. 5). По формуле Вульфа-Брэгга рассчитали межслоевое расстояние в этом образце, которое оказалось равным 15,4 А, что вдвое больше, чем расстояние между слоями в исходном гидроксиде никеля. На рентгенограмме образца 3 наблюдается малозаметный максимум, что можно объяснить небольшим количеством внедренного вещества или, вероятно, тем, что молекула катионного ПАВ адсорбировалась на поверхности образца.

На рис. $6 a$ представлены микрофотографии образиа 2, полученные методом просвечивающей электронной микроскопии. Видно, что образец состоит из частиц игольчатой формы

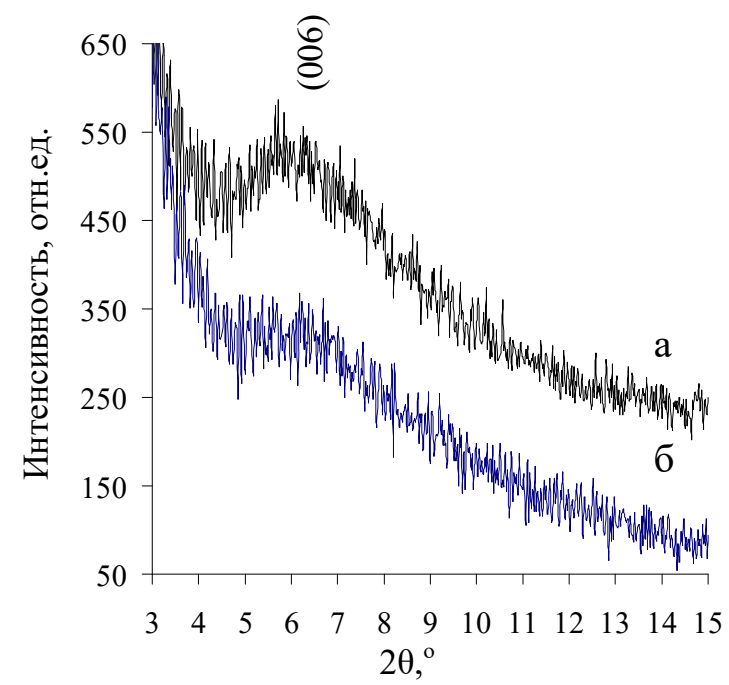

Рис. 5. Рентгенограммы образиа 2 (a) и образиа 3 (б), снятые в малоугловой области

Fig. 5. X-Ray Diffraction patterns of sample 2 (a) and sample 3 (б) obtained in the low angle range

$$
-38-
$$



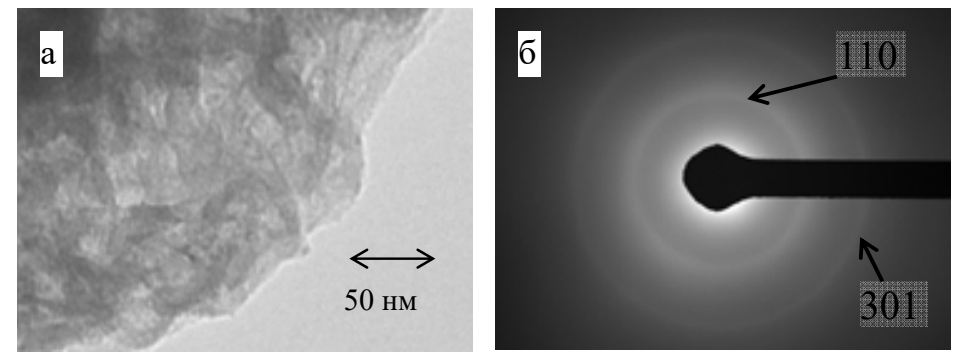

Рис. 6. Микрофотографии ПЭМ частиц $\alpha-\mathrm{Ni}(\mathrm{OH})_{2}$, полученного в присутствии ДСН (а) и его электронограмма (б)

Рис. 6. TEM micrographs of $\alpha-\mathrm{Ni}(\mathrm{OH})_{2}$ particles obtained with sodium dodecylsulfate (a) and its electron diffraction pattern (б)

размером около 50 нм. На электронограмме (рис. 6б) наблюдаются размытые дифракционные кольца, соответствующие плоскостям (110) и (301) $\alpha-\mathrm{Ni}(\mathrm{OH})_{2}$, что характерно для поликристаллических материалов с малым размером кристаллитов (рассчитанный нами по формуле ДебаяШеррера размер полученных частиц равен 2 нм).

\section{Заключение}

Таким образом, в результате проведенного исследования получены гибридные органонеорганические материалы на основе $\alpha-\mathrm{Ni}(\mathrm{OH})_{2}$. Установлено, что материал на основе $\alpha-\mathrm{Ni}(\mathrm{OH})_{2}$ и додецилсульфат-иона имеет наибольшую долю органической фазы и межслоевое расстояние $15,4 \AA$ А. По данным электронной микроскопии, средний размер частиц образца составил 50 нм, размер кристаллитов, рассчитанный на основе данных РФА, равен 2 нм.

Полученные продукты представляют интерес как нанореакторы для направленного синтеза металлических или оксидных наночастиц, находящих широкое применение в качестве катализаторов, компонентов магнитных жидкостей, носителей лекарственных препаратов.

В работе использованы приборы Центров коллективного пользования ФИЦ КНЦ СО РАН u $С Ф У$.

Исследование выполнено при финансовой поддержке Российского фонда фундаментальных исследований, Правительства Красноярского края, Красноярского краевого фонда науки в рамках научного проекта № 18-43-243014: “Синтез магнитных наночастии со структурой «ядро-золотая оболочка» для биомедицинских и каталитических приложений».

\section{Список литературы}

1. Nicole L., Boissiere C., Grosso D., Quach A., Sanchez C. Mesostructured hybrid organicinorganic thin films. Journal of Materials Chemistry 2005. Vol. 15, P. 3598-3627.

2. Sanchez C., Ribot F., Lebeau B. Design of hybrid organic-inorganic materials synthesized via sol-gel chemistry. New Journal of Chemistry 1994. Vol. 18, P. 1007.

3. Lebeaua B., Innocenzi P. Hybrid materials for optics and photonics. Chemical Society Reviews 2011. Vol. 40(2), P. 886-906. 
4. Petrova O.B., Avetisov R.I., Khomyakov A.V., Saifutyarov R.R., Akkuzina A.A., Mozhevitina E.N., Zhukov A.V., Avetissov I.Ch. Prospective Electroluminescent Hybrid Materials. European Journal of Inorganic Chemistry 2015. Vol. 7, P. 1269-1274.

5. Помогайло А.Д. Гибридные полимер-неорганические нанокомпозиты. Усnехи химии 2000. T. 69(1), C. 60-89. [Pomogajlo A.D. Hybrid Polymer Inorganic Nanocomposites. Russian Chemical Reviews 2000. Vol. 69(1), P. 60-89. (In Russ.)]

6. Sanchez C., Julian B., Belleville P., Popall M. Applications of hybrid organic-inorganic nanocomposites. Journal of Materials Chemistry 2005. Vol. 15, P. 3559-3592.

7. Song X., Gao L. Facile Route to Nanoporous NiO Structures from the a-Ni(OH) $)_{2} / \mathrm{EG}$ Precursor and Application in Water Treatment. Journal of the American Ceramic Society 2008. Vol. 91(12), P. 4105-4108.

8. Jia D., Gao H., Dong W., Fan S., Dang R., Wang G. Hierarchical $\alpha-\mathrm{Ni}(\mathrm{OH})_{2}$ Composed of Ultrathin Nanosheets with Controlled Interlayer Distances and Their Enhanced Catalytic Performance. ACS Applied Materials end Interfaces 2017. Vol. 9(24), P. 20476-20483.

9. Кудрявцева Г.С. Гибридные материалы на основе органических комплексов металлов и слоистых неорганических соединений: дис. ... канд. хим. наук: 02.00.03. Ин-т элементоорган. соединений им. А.Н. Несмеянова РАН. Москва, 2009. 144 с. [Kudryavceva G.S. Hybrid materials based on organic complexes of metals and layered inorganic compounds. Thesis. Moscow, 2009. 144 p. (In Russ.)]

10. Pikurova E.V., Saikova S.V., Pashkov G.L., Panteleeva M.V., Mikhlin Yu.L. Solvothermal synthesis of $\alpha-\mathrm{Co}(\mathrm{OH})_{2} @$ SDS in n-Octanol Medium. Russian Journal of Inorganic Chemistry 2018. Vol. 63(2), P. 245-250.

11. Пашков Г.Л. Сайкова С.В., Пантелеева М.В., Линок (Пикурова) Е.В., Королькова И.В. Получение кобальтсодержащих (металлических, оксидных) наночастиц методом сольвотермолиза. Журнал Сибирского федерального университета. Техника и технологии 2012. Т. 5(5), C. 579-584. [Pashkov G.L. Sajkova S.V., Panteleeva M.V., Linok (Pikurova) E.V., Korolkova I.V. Synthesis of Cobalt Nanoparticles by Solvothermal Process. Journal of the Siberian Federal University. Technics and techology 2012. Vol. 5(5), P. 579-584. (In Russ.)]

12. Liu Z., Li S., Yang Y., Peng S., Hu Z., Qian Y. Complex-Surfactant-Assisted Hydrothermal Route to Ferromagnetic Nickel Nanobelts. Advanced Materials 2003. Vol. 15(22). P. 1946-1948.

13. Rajamathi J.T., Arulraj A., Ravishankar N., Arulraj J., Rajamathi M. Delamination of Surfactant-Intercalated Brucite-Like Hydroxy Salts of Cobalt and Copper and Solvothermal Decomposition of the Resultant Colloidal Dispersions. Langmuir 2008. Vol. 24(19), P. 11164-11168.

14. Тарасов К.А. Двойные гидроксиды алюминия и лития с комплексами ЭДТА переходных металлов как прекурсоры для синтеза нанофазных металлсодержащих систем: дис. ... канд. хим. наук: 02.00.21. Институт химии твердого тела и механохимии СО РАН. Новосибирск, 2001. 131 c. [Tarasov K.A. Aluminum and lithium double hydroxides with transition metal EDTA complexes as precursors for the synthesis of nanophase metal-containing systems. Thesis. Novosibirsk, 2001. 131 p. (In Russ.)]

15. Интеркалаты. Химическая энциклопедия. Т. 2. Москва: Советская энциклопедия, 1990. C. 243. [Intercalats. Chemical encyclopedia. Vol. 2, Moscow: Soviet encyclopedia 1990. P. 243. (In Russ.)] 
16. Newman S.P. Jones W. Synthesis, characterization and applications of layered double hydroxides containing organic guests. New Journal of Chemistry 1998. Vol 22(2), P. 105-115.

17. Hall D.S., Lockwood D.J., Bock C., MacDougall B.R. Nickel hydroxides and related materials: a review of their structures, synthesis and properties. Proceedings of the Royal Society A: Mathematical, Physical and Engineering Sciences 2014. Vol. 471(2174), 65 p.

18. Ida S. Shiga D., Koinuma M., Matsumoto Y. Synthesis of hexagonal nickel hydroxide nanosheets by exfoliation of layered nickel hydroxide intercalated with dodecyl sulfate ions. Journal of the American Chemical Society 2008. Vol. 130(43), P. 14038-14039.

19. Третьяков Ю.Д., Лукашин А.В., Елисеев А.А. Синтез функциональных нанокомпозитов на основе твердофазных нанореакторов. Успехи химии 2004. Т. 73(9), С. 974-998. [Tretyakov Yu.D., Lukashin A.V., Eliseev A.A. Synthesis of functional nanocomposites based on solidphase nanoreactors. Advances in chemistry 2004. Vol. 73(9), P. 974-998 (In Russ.)]

20. Liu B.-H., Yu S.-H., Chen S.-F., Wu C.-Y. Hexamethylenetetramine Directed Synthesis and Properties of a New Family of $\alpha$-Nickel Hydroxide Organic-Inorganic Hybrid Materials with High Chemical Stability. The Journal of Physical Chemistry B. 2006. Vol. 110(9), P. 4039-4046.

21. Li H., Liu S., Huang C., Zhou Z., Li Y., Fang D. Characterization and supercapacitor application of coin-like $\beta$-nickel hydroxide nanoplates. Electrochimica Acta 2011. Vol. 58, P. 89-94.

22. Nethravathi C., Ravishankar N., Shivakumara C., Rajamathi M. Nanocomposites of $\alpha$-hydroxides of nickel and cobalt by delamination and co-stacking: Enhanced stability of $\alpha$-motifs in alkaline medium and electrochemical behavior. Journal of Power Sources 2007. Vol. 172(2), P. 970-974.

23. Pashkov G.L., Saikova S.V., Panteleeva M.V. Reactive ion exchange processes of nonferrous metal leaching and dispersion material synthesis. Theoretical Foundations of Chemical Engineering 2016. Vol. 50(4), P. 575-581.

24. Pashkov G.L., Saikova S.V., Panteleeva M.V., Linok (Pikurova) E.V. Ion-exchange synthesis of $\alpha$ - modification of nickel hydroxide. Theoretical Foundations of Chemical Engineering 2014. Vol. 48(5). P. 671-676.

25. Линок (Пикурова) Е.В., Пашков Г.Л., Сайкова С.В., Пантелеева М.В., Жижаев А.М., Козлова С.А. Синтез гибридных органо-неорганических материалов на основе гидроксида кобальта (II), полученного с использованием анионообменной смолы. Известия ВУЗов: Химия и химическая технология 2015. T. 58(1), С. 45-49. [Linok (Pikurova) E.V., Pashkov G.L., Sajkova S.V., Panteleeva M.V., Zhizhaev A.M., Kozlova S.A. Synthesis of hybrid organo-inorganic materials based on cobalt (II) hydroxide, obtained using anion-exchange resin. University news: Chemistry and chemical technology 2015. Vol. 58(1), P. 45-49 (In Russ.)]

26. Torresi R.M., Vazquez M.V., Gorenstein A., de Torresi S.I.C. Infrared characterization of electrochromic nickel hydroxide prepared by homogeneous chemical precipitation. Thin Solid Films 1993. Vol. 229(2), P. 180-186.

27. Park H.W., Chae J.S., Park S.-M., Kim K.-B., Roh K.C. Nickel-Based Layered Double Hydroxide From Guest Vanadium Oxide Anions. Metals and Materials International 2013, Vol. 19(4), P. 887-894. 